\title{
Childcare Worker's Understanding of the Play Cycle theory: can a focus on 'process not product’ contribute to quality childcare experiences?
}

\author{
Word Count 5793
}

\begin{abstract}
Background: Since the 1990s there has been an exponential growth in childcare provision in the UK, particularly for school-aged children. There has also been a growing interest in the conceptualisation and measurement of quality of childcare and the professionalisation of the childcare workforce. Previous studies have found that one of the most important areas of quality from a children's perspective is the provision of play and the adult role in supporting play within childcare settings. Aim: The aim of this study was to investigate childcare workers understanding of the Play Cycle theory (Sturrock \& Else, 1998).
\end{abstract}

Method.: Childcare workers were invited to take part in an on-line survey to find out how they were introduced to the Play Cycle, how they would define the six elements (metalude, play cue; play return; play frame; loop and flow and annihilation), the adult role in the Play Cycle and if it has had any impact on childcare practice.

Results: Childcare worker's introduction to the Play Cycle is mostly through a childcare qualification. There was a significant relationship between childcare practitioners not having an understanding of two elements of the Play Cycle, the metalude and the play frame. There was a significant relationship between childcare managers and development officers understanding of the metalude to variation 1 and the play frame to variation 2 .

Conclusions. The findings indicate that the Play Cycle can help childcare workers support children's play. This has potential implications for children's perception of the quality of their childcare settings. Recommendation. There is a need for the theory of the Play Cycle to be more widely understood within the childcare sector. 


\section{Key Words: Childcare; Play Cycle; Play; Playwork; Professional Practice}

\section{Introduction}

Childcare is a type of provision which looks after children whilst parents and carers work, study or in need of some form of respite. Within a UK context, childcare is defined as "any form of care for a child ... (a) education for a child, and (b) any other supervised activity for a child” (UK Government, 2006, p. 10). In childcare provision, there is a 'contract' between the childcare organisation and the parent/carer, where the organisation has responsibility for the care of the child for an agreed period of time. Since the 1990s there has been an exponential growth in childcare provision in the UK, particularly for school-aged children, where many forms of childcare exist (West \& Noden, 2016):

- Day Care, for example nurseries where children may be cared for from as early as 8am to $6 \mathrm{pm}$

- Before and After School clubs which sandwich between primary school hours (usually 9am to $3.30 \mathrm{pm}$ ) and holiday playschemes which run during school holidays (often 8am to 6pm)

- Pre-school and playgrounds which may be funded through government initiatives e.g. SureStart (Department for Education (DfE), 2013) and Flying Start (Welsh Government (WG), 2014).

The different types of childcare provision thus vary in the age range of children attending, the number of hours run and whether funding is available to help support running costs. In England and Wales, childcare provision is closely regulated under the Children Act 1989 (Legislation.gov.uk, 2018a) and the Childcare Act 2006 (Legislation.gov.uk, 2018b) which includes guidance on quality, staffing qualifications and children’s play opportunities.

Inspection of childcare is undertaken in England by the Office for Standards in Education (Ofsted) and in Wales by the Care Inspectorate Wales (CIW) (Welsh Government (WG), 2016). Regulation in 
England is for any childcare provision that runs for four hours or more in any day and cater for children under 8 years old of age and are required to meet the 14 national standards for day care (SureStart, 2003). Provision in England that run for less than 2 hours a day, e.g. out of school clubs, or only cater for children 8 years or over are not required to register the provision. Standard 1 'Suitable Person’ requires the manager and supervisors to have at least a level 3 qualification (SureStart, 2003). In addition, the manager must have “at least 2 years' experience of working in a day care setting” (SureStart, 2003, p.9). Standard 3 ‘Care, Learning and Play’ states the need to "plan and provide activities and play opportunities to develop children's emotional, physical, social and intellectual capabilities” (SureStart, 2003, p.12).

In Wales, childcare for more than 2 hours a day, more than 5 days a week and with children up to the age of 12 years must register their childcare provision and be inspected to meet 24 national standards (WG, 2016). Standard 13 relates to ‘Suitable Person’ where "the person in charge has at least a level 3 qualification” (WG, 2016, p.35) and the provision, Standard 7 focuses on 'Opportunities for Play and Learning' where “Children have a range of experiences, including freely chosen, unstructured and self-directed play, that contribute to their emotional, physical, social, intellectual, language and creative development” (WG, 2016, p.24) and Standard 18 ‘Quality Assurance’ where “Children and their parents benefit from a quality service that is effectively monitored” (WG, 2016, p.43).

Quality is an important factor in both the inspection of childcare settings and for parents faced with choices about which childcare setting will be best for their children (Widdows \& Powell, 1990). However, quality is often measured in terms of what adult's think is important, such as academic, social and school readiness (Winsler et. al., 2006), predicting behaviour and social competence (Pluess \& Belsky, 2009), social development (Howes, Phillips \& Whitebook, 2006) and childcare worker's recruitment and retention (Rolfe, Metcalfe, Anderson, \& Meadows, 2003). However, as Mooney and Blackburn's (2003) identified through their study on children's views of quality childcare using a combination of individual interviews, focus groups, drawings, photographs, tours, role-play and story-telling using a puppet, children also have a clear view of quality, where: 
All children said how much they liked the staff or their childminder. Younger children want staff who are caring, friendly, helpful and playful. Children in centre-based care said that they do not like staff being in the office too much. Older children prefer staff to have the following characteristics: are fun, play and join in with them, are nice and kind, help them, give them freedom and responsibility, treat children with respect and fairness, take children seriously, like and get on with children, be interested in lots of different things, look after them, be their friend, listen and talk to children. They dislike staff who talk among themselves, do not participate in activities and who are restrictive and controlling (Mooney and Blackburn, 2003, p. 20-21).

From both the review of the literature and their own study, Mooney and Blackburn (2003) identified how important children and young people consider the role of the childcare worker in supporting their play. Children preferred childcare workers who are playful, which suggests more emphasis on the process determinants, rather than focusing on structural outcomes. This aspect of childcare workers being playful was also identified as important in Brownlee et. al's. (2006) small-scale observational study on Australian childcare workers and children interaction. Using a quality assessment 'Checklist of Intervention' they devised based on the theoretical framework of Henry (1996), childcare workers scored highly on the observed element of 'Engages in playful interactions with children (e.g. interactions have elements of fun and light-heartedness)'. The importance of fun in adult-child interactions from a child's perspective was also found from a childcare worker perspective:

Many childcare workers referred to the 'fun' of working with children, and this aspect, of never knowing exactly what would happen was viewed as very positive. Working with older children in out of school and holiday schemes was also found to be 'fun' because activities were designed to keep children and young people engaged and entertained (Rolfe, Metcalfe, Anderson, \& Meadows, 2003, p.66). 
From the studies briefly discussed above, children see play as an important indicator of quality in the childcare provision they are attending. In order to meet children's expectations of quality in childcare settings, childcare workers' understanding of their role in providing and facilitating play needs to be considered. This aspect of the practitioner having an understanding of their role in children's play has recently been researched by King and Newstead (2019a, 2019b) in relation to playworker's understanding of the Play Cycle theory (Sturrock \& Else, 1998) and whether knowledge and understanding of this theory has any impact on playwork practice.

The Play Cycle is a theoretical model of play that considers the interaction between adults and children (King \& Temple, 2018). The Play Cycle currently informs the eight Playwork Principles (PPSG, 2005) and underpins both playwork training and professional practice (for more detail see King \& Sturrock, 2019). As outlined by Sturrock and Else (1998), the Play Cycle describes play as a process rather than focusing on it as an outcome (Howard \& King, 2014, Neumann, 1971). The Play Cycle consists of six elements: metalude; play cue; play return; play frame; loop and flow and annihilation. A study undertaken by King and Newstead (2019a, 2019b) on 157 playworker's understanding of the Play Cycle found that there was a variation in how playworkers defined the six elements. Although there was variation in understanding, most playworkers felt that the Play Cycle theory had made a positive impact on their practice in that they took a more observant and reflective role and only intervened in a play cycle when invited (King \& Newstead, 2019a).

There is much debate about the similarities and differences between playwork and childcare. Playwork was introduced as a National Occupational Standard (NOS) for those working in afterschool clubs opened in the 1990s where there was a lack of professional qualification for adults working with children in out of school settings. However, for some playworkers this was a travesty of the 'three-frees criteria' of: “free to access, activities should be freely chosen by the children and they should be free to leave when they wish” (Else, 2009, p157). In after-school clubs, children were not free to come and go as they pleased as parents and carers had to pay for the childcare service. Furthermore, in after-school club’s children were not free to do as they wished, as the newly qualified 
playworkers provided structured programmes of activities rather than 'free play' (Morgan, 1999. This new variation on the theme of playwork has created much debate and the tension for the playwork field ever since (Hughes, 2001, Lester, 2016).

This paper posits that quality in childcare settings could be improved from a children's perspective if childcare workers were more informed about the Play Cycle theory. This study aimed to replicate the online survey for playworkers undertaken by King and Newstead (2019a, 2019b) to find out childcare workers' knowledge and understanding of play as a process using the Play Cycle theory, with the following research questions:

1. What are childcare worker's understanding of the Play Cycle?

3. What is the childcare worker's role in the Play Cycle?

\section{Method}

This study was granted ethical approval by the ethics committee within the College of Human and Health Science at Swansea University in August 2018.

Whether a practitioner calls themselves a playworker or childcare worker can be down to their job description or personal preference. It was therefore stated that anybody who had already completed the playworker version of the online survey must not complete this survey. One hundred and eightysix childcare workers accessed the survey, but only 52 participants completed it. From the 52 completed surveys, 26 were from England, 18 from Wales and there was a combined number of 8 for Scotland, Northern Ireland, Republic of Ireland and outside the United Kingdom and Republic of Ireland. As the number outside England and Wales was low and would not provide any meaningful representation, it was decided to focus on childcare workers in England and Wales only for statistical analysis. The total number of participants completing the online survey from England and Wales was 44. These could be broken down to 17 childcare practitioners, 5 childcare educators and 22 childcare managers or development officers. For statistical analysis, the 5 childcare educators were removed 
which left a total of 39 participants and Figure 1 shows the demographic comparison of childcare workers between England and Wales.

\section{[Insert Figure 1 Here]}

The data was collected using an online survey replicating a prior study with playworkers (King \& Newstead, 2019), where the term 'childcare worker' replaced the original term 'playworker'. The online survey was constructed using the qualtrics ${ }^{\circledR}$ survey application and was open to all childcare workers worldwide which included childcare practitioners, trainers, lecturers and volunteers. An online survey was used as it enabled circulation through international, national and local childcare networks and social media, and all data collected was anonymous. To access the survey, participants had to click on the link accessed via any electronic device. The online survey collected quantitative demographic data with respect to years of practice, current qualification, job role and location of practice. The qualitative data collected included where childcare workers first heard about the Play Cycle, publications read about the Play Cycle theory, what they perceived to be the adult role within the Play Cycle and how they would define the six elements of the metalude, play cue, play return, play frame, loop and flow and annihilation.

The responses were analysed using descriptive statistics and content analysis (Cole, 1998). Descriptive statistics were undertaken for demographic analysis whilst content analysis used four categorisation matrixes (Elo \& Kynga, 2007) developed by King and Newstead (in progress, in press). The categorisation matrixes enabled coding to pre-determined themes for how childcare workers first heard of the Play Cycle, definitions of the six elements (meta-lude, play cue, play return, play frame, loop and flow and annihilation), the adult role in the Play Cycle (Table 3) and any impact of the Play Cycle on practice. 
For content analysis, broad groups are needed (Cole, 1988). The first broad group was the location of England and Wales. Initial analysis of the demographic data for childcare workers in England and Wales showed years of practice formed two broad groups, 0-10 years and 11+ years. For main childcare role, two groups were used, childcare practitioner and childcare management and development. All respondents had one form of childcare qualification; therefore, two broad groups were formed, up to level 3 and level 4-8.

An initial Pearson’s Chi Square test for association (Ugoni \&Walker, 1995) was undertaken to investigate any relationship between years of childcare practice, current childcare role, highest childcare qualification and location of childcare practice. A second Chi Square analysis was undertaken to investigate any relationships with years of practice, childcare role, highest qualification and location with each of the six components of the Play Cycle.

\section{Results}

\section{First Heard of the Play Cycle}

Childcare workers were asked to write down where they first heard of the Play Cycle. Each was response was coded to a categorisation matrix developed by King and Newstead (2019) which has five themes: In-House Training; External Training; Coursework; Self-Initiated and Never Heard of It. Each response was coded by one of the researchers to one theme only and this is shown in Table 1:

\section{[Insert Table 1 Here]}

From the combined 39 practitioners and management and development, 2 participants were introduced to the Play Cycle through in-house training, 2 through external training, 17 as part of their coursework, 7 by self-interest and 11 had stated they had not heard of it. The data set was coded independently by the second researcher to the categorisation matrix and the results were compared for 
inter-rater reliability using Cohen’s Kappa statistical analysis. Cohen’s Kappa (k) is an inter-rater reliability statistical test which compares the scores from two independent researchers where a value from -1 to +1 is obtained, where +1 is a perfect agreement between each rater (McHugh, 2012). The inter-rater reliability between the two coders for Cohen's Kappa was $\kappa=0.94$ (95\% CI, 0.89 to 0.99), $\mathrm{p}<0.001$ which indicates an almost perfect agreement (Landis \& Koch, 1977).

\section{Six Elements of the Play Cycle}

King and Newstead (in progress) developed a categorisation matrix for each of the six elements of the Play Cycle (metalude; play cue; play return; play frame; loop and flow and annihilation) based on the original ‘Colorado Paper’ and published texts (see Table 2):

\section{[Insert Table 2 Here]}

For each element of the Play Cycle, the same process of each response was independently coded by the two researchers and a Cohen’s Kappa statistical test was undertaken for inter-rater reliability. For this analysis, any disagreement of coding was discussed as each element had three closely matching definitions. Where an agreement was reached, the code was changed.

Cohen's Kappa $\kappa$ was run to determine if there was agreement between the two researchers for each element of the Play Cycle. There was a perfect agreement for the Metalude $\kappa=1.00$ ( 95\% CI, 0.00 to $0.00), \mathrm{p}<0.001$ and near perfect agreement for the play cue $\kappa=0.90(95 \% \mathrm{CI}, 0.80$ to 1.0$), \mathrm{p}<0.001)$, play return $\kappa=0.87$ (95\% CI, 0.74 to 1.0$), \mathrm{p}<0.001$, play frame $\kappa=0.93$ (95\% CI, 0.85 to 1.0 ), $\mathrm{p}<0.001$, loop and flow $\kappa=0.81(95 \% \mathrm{CI}, 0.86$ to 1.0$), \mathrm{p}<0.001$ and annihilation $\kappa=0.95$ (95\% CI, 0.88 to 1.0$), \mathrm{p}<0.001$.

A Pearson's Chi Square association was undertaken for each element of the Play Cycle with years of practice, current role, location and highest childcare qualification. During the coding process, no 
participant for any of the six elements coded to the 'Colorado Paper') for metalude, play cue, play return, play frame and loop and flow. For annihilation, three people were coded for the 'Colorado Paper’. For the Chi Square analysis, the three coding to the 'Colorado Paper' were removed as any count below 5 would violate any significant results obtained.

The Pearson’s Chi Square performed to examine the relationship between childcare role and the metalude found a significant relation between these variables, $x^{2}(1, N=39)=4.92, p<0.05$. The childcare practitioner was more likely not to understand or provide a different definition (adjusted residue 2.2), whilst the childcare manager and development officer were more likely to provide define the metalude to variation 1 (adjusted residue 2.2). A Pearson's Chi Square also found a relationship between childcare role and the element of the play frame, $x^{2}(1, N=36)=4.62, p<0.05$. Childcare practitioners were more likely to not understand the play frame or provide a different definition (adjusted residue 2.2), whilst childcare managers and development officers would use Variation 2 (adjusted residue 2.2).

One aspect that may need further consideration is the relationship between the childcare role and the annihilation. The Chi Square performed between these two variables indicated a significant relationship ( $\mathrm{p}<0.05$ ). However, more than $20 \%$ had an expected count of less than 5 , thus making the result invalid.

\section{The Childcare Role in the Play Cycle and Impact of the Play Cycle on Childcare Practice}

The online survey asked for participants to write down what they felt was the adult role in the Play Cycle. Responses were matched to the categorisation matrix based on the hierarchy of adult intervention (Sturrock \& Else, 1998) of play maintenance, simple involvement, medial intervention and complex intervention as defined by Sturrock, Russell and Else (2004):

\section{[Insert Table 3 Here]}


Unlike coding with the other categorisation matrixes within this paper, coding for each participant could contain one, two, three or all four levels of adult intervention. For example, this one comment from a participant sums up the three aspects of play maintenance (observe), simple involvement (act as a resource) and medial intervention (wait to be 'cued in', and if appropriate, 'remove themselves' from the Play Cycle):

"The adult should observe the cycle and only be part of it if the play cue was aimed at them. Once the children are engaged in the play the adult should remove themselves and support the play frame by ensuring it is not interrupted or by providing resources to develop the play frame."

Not all the responses could be coded to the Sturrock \& Else’s (1998) level of hierarchy. 17 participants described the adult role in supporting children's learning, as demonstrated in the comment below:

"The adult is there to support the child in their learning, not to direct the play"

Sturrock and Else (1998) do not include the adult role in the Play Cycle as supporting children's learning. Although play may support children's learning, the Play Cycle focuses more on the process of play rather than play as an outcome (Howard \& King, 2014).

Coding for the adult role was undertaken independently between the two researchers. As the number of variations exist (coding to 1, 2, 3 or all 4 hierarchy with the addition category of 'none of the above’), it is not possible to carry out an inter-rater reliability using Cohen’s Kappa. Instead, a 
comparative can be undertaken by adding up the total number of codes by each researcher and finding the average for each level of hierarchy. This enables a percentage comparison for each level as shown in Table 4 below:

\section{[Insert Table 4 Here]}

There was a close comparison on the percentage scores between the two researchers: play maintenance $29 \%$ and 32\%, simple involvement $29 \%$ and 25\% and medial intervention 33\% and 35\%. For complex intervention and none of the above, this required discussion as initially researcher 1 coded 0 for complex intervention, whilst researcher two coded for 7 . The discussion revolved around whether the use of the Play Cycle being specifically stated in context of a learning outcome or education. The 'Colorado Paper' (Sturrock \& Else, 1998) and the use of the hierarchy of intervention is based on supporting children's play, but not from an adult agenda. Learning outcomes and education are adult agendas. It was decided that a category of none of these is where any mention or use of the Play Cycle for educational purposes would be placed. For complex intervention, this resulted in an overall agreement of $0 \%$ and $2 \%$ and for none of these $9 \%$ and $6 \%$. What was evident was that some childcare workers felt that the role of the adult should focus on play and learning outcomes for the child, rather than supporting the process of play.

Childcare workers were asked to write down if they thought the Play Cycle had any impact on their practice. Each was response was coded to a categorisation matrix developed by King and Newstead (in progress) and this is shown in Table 5:

\section{[Insert Table 5 Here]}

The results found 19 childcare workers felt the Play Cycle had changed their practice. 3 related the impact to focusing more on the child's play behaviour, 5 found the theory underpinned their practice and 12 felt it had not had any impact on their practice. A Cohen’s Kappa inter-rater reliability to 
determine if there was agreement between the two researchers and the adult role in the Play Cycle was $0.90(\mathrm{p}<0.000), 95 \%$ CI $(0.80,0.90)$. This indicates an almost perfect agreement (Landis and Koch, 1977). The following comments reflect the results:

"More observant, less impulsive to jump in and disrupt the play unintendedly." (Changed Practice)

"Yes, I would say it has helped me understand and follow the recent guidance on child led play, children leading learning.” (Play Behaviour)

“The Play Cycle has put on paper the way I have always worked.” (Provide Underpinning Theory)

"No.... it’s outdated and doesn’t reflect how play works between children and adults.” (Nothing)

One strength of this study was the easy application of the three categorisation matrices developed from the online Play Cycle with playworkers (King \& Newstead, 2019a; 2019b), which could also be used in future studies. This provides an important aspect of trustworthiness with respect to credibility, transferability, dependability and confirmability of this study (Shenton, 2004). However, one limitation was the small sample size from this online survey of 52 participants. It should also be noted that, unlike playwork, where the Play Cycle is grounded in the NOS within the Playwork Principles (PPSG, 2005), knowledge of the Play Cycle is not required in professional childcare qualifications and therefore does not have a direct link to professional practice, unless students take a specific module that has a link to playwork.

\section{Discussion}

This aim of this study was to investigate childcare workers understanding of the Play Cycle (Sturrock \& Else, 1998), replicating a previous online survey on playworker's understanding of the Play Cycle 
with playworkers (King \& Newstead, 2019a; 2019b). Two research questions were developed: What are childcare worker's understanding of the Play Cycle? What is the childcare worker's role in the Play Cycle? From a previous study, variation in playworker's understanding was found in how they defined the different elements of the Play Cycle (metalude, play cue, play return, play frame, loop and flow and annihilation). Thus, a further study in a different, but closely linked profession of childcare was undertaken. The study also found variations in childcare worker's understanding of the elements of the Play Cycle, with a relationship between the childcare role and understanding of the metalude and the play frame. Most childcare workers stated that the Play Cycle had a positive effect on their practice, although rather than the adult supporting the process of play as envisaged by the original theory, respondents felt that the role of the adult was to support children's learning, thus focusing more on the outcomes of play, rather than the process.

When childcare workers were asked how they first heard of the Play Cycle, most stated this was through undertaking coursework for a childcare qualification. This differed from the playworker online survey, where most had first heard of the Play Cycle through their workplace (King \& Newstead, 2109a). This difference would reflect the requirement of childcare workers to be qualified to level 3 for supervisors and level 4 for managers in England and Wales (SureStart, 2003; Welsh Government, 2016) whilst in England, not all playwork provision must adhere to these standards. What is important to consider here is the published texts or online information childcare workers are accessing to support their qualifications, as it has been shown there is variation in the coursework texts on how the Play Cycle is being interpreted (King \& Newstead, 2019). If childcare workers first learn about the Play Cycle theory through published texts or online research, they may learn different iterations of the theory depending on which source they read. This would then lead to different understandings of the theory according to which course is undertaken.

This study found that childcare practitioners did not have a clear understanding of the metalude or play frame, whereas childcare managers and development officers defined these two elements to variation 1 and 2 respectively. Therefore, as with the playworker study, this study found a variation 
in understanding of key elements in the Play Cycle theory. King and Newstead (2019) offer revised definitions of the six elements of the Play Cycle, which could support both playworker's and childcare worker's understanding of the Play Cycle to support a more playful approach to supporting children's play, which is an important indicator of quality in childcare settings for children (Brownlee et al., 2006).

The Play Cycle theory aims to support children's free play rather than meet pre-defined outcomes (Sturrock \& Else, 1988). Childcare workers stated that the Play Cycle had changed their practice, in that following learning about the Play Cycle theory, they would take a less active and more observational role. However, nearly $50 \%$ of survey respondents stated how the adult role would support children's learning. This reflects a view of play as a process by some childcare workers, and as an outcome by others. Childcare has in recent years developed a close relationship with education which can be seen in both the 14 Standards in England (SureStart, 2003) and 24 Standards in Wales (WG, 2016), where the term 'Educare' has evolved (Bass \& Good, 2004). Within an educational context, practitioners focus their play interaction on structural outcomes, such as children's cognitive learning, rather than, for example, how children socially interact when playing (File, 1994). This is not a criticism but reflects the contrasting role childcare workers have in respect to meeting the national standards for childcare, where play and learning are closely linked. However, from a playwork perspective, the Play Cycle theory positions any outcomes from play as 'secondary' to the process of play itself. A more process-focus on play would entail the childcare worker in observing and facilitating play rather than taking the lead in order to achieve educational outcomes. More knowledge of the Play Cycle theory may then create tensions within the role of the childcare worker as educator or playworker and lead to difficulties in demonstrating compliance with regulatory requirements. This raises the question of whose views of quality in childcare really matter - the adult providers and regulators, or the children who can find themselves in childcare settings for many weeks of the year. 
Process focused views were reflected in the aspects of play maintenance; simple involvement and medial intervention (Sturrock \& Else, 1988), where the childcare worker takes on a role as an observer, a resource or wait to be invited to play. Within childcare provision, it is not uncommon for only 2 adults to look after 16 children. Thus it would be extremely difficult for childcare workers to be involved in a Play Cycle with an individual child, playing out a socio-dramatic game for example (see King \& Temple, 2018). However, the play intervention styles of play maintenance, simple involvement and medial intervention can provide a useful framework for childcare workers to focus on the process of play. For example, childcare workers who considered the Play Cycle changed their practice by being more observant or acting as resource with respect to play maintenance and simple involvement (Sturrock \& Else, 2004), which focuses on supporting the process of play.

Quality childcare provision is a need to meet national minimal standards (SureStart, 2003; WG, 2016) and playfulness in childcare staff has been identified by children to be an important factor (Mooney \& Blackburn, 2003). This small-scale survey with 52 childcare workers from England and Wales has shown that, for some, the introduction to the Play Cycle has seen a change in practice, although it is still being used for outcome focused play. As was seen with the playworker survey (King \& Newstead, 2019b), there is variation in childcare worker's understanding of the six elements within the Play Cycle. Childcare workers could develop a more playful approach to supporting the process of children's play (Howard \& King, 2014) through knowledge of the Play Cycle theory, which could improve the quality of childcare provision in children's terms.

\section{Conclusion}

In relation to quality, children recognise the playful nature of adults as important, and hence a more process than outcome-focused consideration of play can provide a different approach for childcare workers to support children's play. It is evident the Play Cycle, whilst common place in playwork, is still a little-known area in childcare. Where the Play Cycle theory was known, the adult role in the Play Cycle was identified by a large number of the sample participants as enhancing learning, rather 
than supporting the process of play. Two areas for further consideration are therefore raised by this study. Firstly, that a wider use of the Play Cycle theory in childcare may lead to a greater understanding of play as a process rather than an outcome. Secondly, a greater understanding of the theoretical and practical implications of play as a process may improve children's assessments about the quality of their childcare experience. Further research is needed with a much larger sample size to determine whether the Play Cycle theory could improve the quality of children's experiences of childcare provision.

\section{References}

Bass, R. V. \& Good, J. W. (2004). Educare and Educere: Is a Balance Possible in the Educational System? The Educational Forum, 68, 161-168.

Brownlee, J. M., Berthelsen, D. C. \& Segaran, N. (2007). Childcare workers' and centre directors' beliefs about infant childcare quality and professional training. Early Child Development and Care, 179(4), 453-475.

Cole FL. (1988) Content analysis: process and application. Clinical Nurse Specialist 2(1), 53-57.

Department for Education (2013). Sure Start children's centres statutory guidance For local authorities, commissioners of local health services and Jobcentre Plus, accessed at https://assets.publishing.service.gov.uk/government/uploads/system/uploads/attachment data/ file/678913/childrens_centre_stat_guidance_april-2013.pdf.

Else, P. (2009). The Value of Play. London: Continuum.

File, N. (1994). Children’s Play, Teacher-Child Interactions, and Teacher Beliefs in Integrated Early Childhood Programmes. Early Childhood Research Quarterly, 9, 223-240.

Henry, M. (1996). Young children, parents and professionals: Enhancing the links in early childhood. London: Routledge.

Howard, J. \& King, P. (2014). Re-establishing early years practitioners as play professionals. In J. Moyles (Ed.) (2014) The Excellence of Play $4^{\text {th }}$ Edition (pp. 125-137). Maidenhead: Open University Press. 
Howes, C., Phillips, D. A. \& Whitebook, M. (2006). Thresholds of Quality: Implications for Social Development of Children in Centre-Based Child Care. Child Development, 63(2), 449-460.

Hughes, B. (2001). Evolutionary Playwork and Reflective Analytical Practice. London: Routledge.

King, P. \& Newstead, S. (2019a).

King, P. \& Newstead, S. (2019b).

King, P. \& Sturrock, G. (2019). The Play Cycle: Theory, Research and Application. London: Routledge.

Legislation.gov.uk (2018a). Child Act (1989) accessed at https://www.legislation.gov.uk/ukpga/1989/41.

Legilsation.gov.uk (2018b). Childcare Act (2006) accessed at http://www.legislation.gov.uk/ukpga/2006/21/pdfs/ukpga 20060021 en.pdf.

Lester, S. (2016). The value of playwork provision in Manchester accessed at http://eprints.glos.ac.uk/3895/7/The\%20value\%20of\%20playwork\%20provision\%20in\%20M anchester.pdf

Mooney, A. \& Blackburn, T. (2003). Research Report No. 482: Children’s Views on Childcare Quality. Nottingham: DfES Publications.

Pluess, M. \& Belsky, J. (2009). Differential susceptibility to rearing experience: the case of childcare. Journal of Child Psychology and Psychiatry 50(4), 396-404.

Rolfe, H., Metcalfe, H., Anderson, T. \& Meadows, P. (2003). Research Report No. 409: Recruitment and Retention of Childcare, Early Years and Play Workers: Research Study. Nottingham: DfES Publications.

Shenton AK. (2004) Strategies for ensuring trustworthiness in qualitative research projects. Education for Information 22, 63-75

SureStart (2003). Full day care: National standards for under 8s day care and childminding accessed https://xx.iriss.org.uk/sites/default/files/resources/Full\%20day\%20care.pdf.

Welsh Government (2014). Flying Start Annex - Quality Childcare Guidance, accessed https://gov.wales/docs/dsjlg/publications/130926fsannex2en.pdf. 
Welsh Government (2016). National Minimum Standards for Regulated Childcare for children up to the age of 12 years, accessed https://careinspectorate.wales/sites/default/files/201801/160411regchildcareen.pdf.

West, A. \& Noden, P. (2016). Public funding of early years education in England: An historical perspective. Clare Market Papers, 21. London School of Economics and Political Science, Department of Social Policy, London, UK. ISBN 978-1-909890-37-4

Widdow, R. and Powell, D. R. (1990). Cost and Quality Factors in Parents' Choice of After-School Child Care. Journal of Consumer Affairs, 24(2), 381-391.

Winsler, A., Trana, H., Hartmana, S. C., Madiganc, A. L., Manfra, L. \& Bleiker, C. (2009). School readiness gains made by ethnically diverse children in poverty attending center-based childcare and public school pre-kindergarten programs. Early Childhood Research Quarterly, 23, 314-329. 